\title{
Subsidence associated with land use changes in urban aquifers with intensive extraction
}

\author{
Briseida Lopez-Alvarez ${ }^{1}$, José Alfredo Ramos-Leal ${ }^{2}$, Germán Santacruz-De Leon ${ }^{1}$, \\ Janete Morán-Ramirez ${ }^{3}$, Simón Eduardo Carranco-Lozada ${ }^{3}$, Cristina Noyola-Medrano ${ }^{4}$ \\ ${ }^{1}$ Water and Society Program, College of San Luis C. A. (COLSAN), San Luis Potosí, México \\ ${ }^{2}$ Applied Geosciences Division, Potosin Institute of Scientific and Technological Research, C.A. (IPICYT), San Luís Potosí, México; \\ jalfredo@ipicyt.edu.mx \\ ${ }^{3}$ Pg Postgraduate Applied Geoscience, Potosin Institute of Scientific and Technological Research, C.A. (IPICYT), San Luís Potosí, \\ México \\ ${ }^{4}$ Faculty of Engineering, University of San Luis Potosí (UASLP), San Luis Potosí, México
}

Received 21 December 2012; revised 19 January 2013; accepted 5 February 2013

\begin{abstract}
Land use change is a major factor in alterations in natural processes and cycles. Remote sensing has become an excellent tool to evaluate technological changes in land cover and land use changes over large areas, such as those occurring in the Valley of San Luis Potosi (VSLP). Here, such changes have impacted a system which is $95 \%$ dependent on the aquifer. The methodology for the present study is based on the use of satellite images for the years 1976, 1986, 1995 and 2000. To asses land use change, a supervised classification process was used with a decision tree technique and ENVI 4.3 software. The evolution of groundwater levels for the years 1977, 1986, 1995, 1998 and 2007 was also analyzed, as well as problems of subsidence and fissuring in the urban area of the valley in 2006. With the support of remote sensing, it was possible to analyze the dynamic changes in land use over large areas and highlight their impact on the environment.
\end{abstract}

Keywords: Land Use Change; Mining; Intensive Extraction; Subsidence; Aquifer urban; Arid Zone

\section{INTRODUCTION}

Land use changes resulting from the interaction between people and their environment have become one of the primary factors responsible for altering natural processes and cycles. Land use changes due to urbanization has caused deforestation, soil erosion and a loss of biodiversity and environmental services, and has had a high impact on the degradation and depletion of water resources [1].
Since the 18th century, but more intensely over the past 50 years, humans have changed the world's ecosystems more quickly and extensively than any comparable period in history. It is now recognized that even if land use changes occur locally, they may have global effects on the hydrogeological cycle since, as it has been shown, the quantity and quality of water depend largely on the type of land use in areas that provide for the catchment, flow, storage, provision and renewal of water resources. Furthermore, population growth and economic development create pressures that lead to changes in land use in the basin [2].

In Mexico, land use change is due to different factors. Human activities that cause degradation are deforestation (29\%), inappropriate agricultural practices (28\%) overgrazing (35\%), extraction of fuelwood (7\%) and industry and urbanization (1\%). In addition, agricultural clearings are responsible for $82 \%$ of deforestation [3].

With regard to water resources in Mexico, the National Water Commission monitors more than 215 surface water bodies, of which $5 \%$ of the water quality is acceptable for any type of use, $22 \%$ is acceptable, $49 \%$ is slightly contaminated, $15 \%$ is contaminated, $7 \%$ is highly contaminated and $2 \%$ contains toxic elements [4]. In terms of groundwater, the country officially has 653 aquifers, 100 of which are overexploited; 53.6\% of groundwater is extracted from these aquifers for all uses [5]. Furthermore, while groundwater is the water source for 75 million Mexicans, little is known about its quality [6].

One way to study these alterations is through remote sensing, which among other uses, has become an excellent tool to evaluate changes in land cover and land use in large areas of land. The aim of this paper is to use remote sensing to analyze land use changes and their effects on both the aquifer system and the terrain of the 
Valley of San Luis Potosi (VSLP).

\section{STUDY AREA}

The VSLP is orographically limited to the west and south by the Sierra de San Miguelito (SSM) and to the east by the Sierra de Alvarez (SA). It is part of basin No. 37, called "El Salado" with geographic coordinates $21^{\circ} 54^{\prime} 54^{\prime \prime}$ to $22^{\circ} 28^{\prime} 15^{\prime \prime}$ north latitude and $101^{\circ} 13^{\prime} 44^{\prime \prime}$ to $100^{\circ} 37^{\prime} 08^{\prime \prime}$. The valley is located in the southwestern portion of the state of San Luis Potosi (Figure 1).

Dry climates are predominant in the study area, with types 1) semi-dry, 2) dry and 3) very dry. The average annual rainfall is $351 \mathrm{~mm}$, mean annual temperature is $17.5^{\circ} \mathrm{C}$ and average annual potential evaporation is $2038.7 \mathrm{~mm}[7,8]$.

The VSLP aquifer system is currently one of the most important in the state because it supplies the capital city, where $80 \%$ of the state's production occurs. This system also covers parts of the municipalities of San Luis Potosi (SLP), Soledad de Graciano Sánchez (SGS), Mexquitic Carmona, Cerro de San Pedro and Zaragoza. The total population of these municipalities is 1,122,502 [9], and groundwater supplies $95 \%$ of its water for various uses [10]. Nonetheless, this has not always been the situation. In 1960, 59\% of domestic water came from surface sources and $41 \%$ from the aquifer system [11].

The VSLP aquifer system is of tectonic origin and consists of a graben and horst system. This system consists of two aquifers traditionally called shallow granular and deep fractured volcanic separated by a layer of fine, compact sand with low hydraulic conductivity [12-14]. The granular aquifer includes a perched aquifer which is directly affected by human activity. It is worth mentioning that it is considered to be an urban aquifer, since the wells for extracting groundwater from the deep aquifer are mainly concentrated in the urban zone.

Given the physical, geological, climatic and hydrogeological characteristics of the VSLP aquifer system, it has negligible recharge, which has resulted in the mining

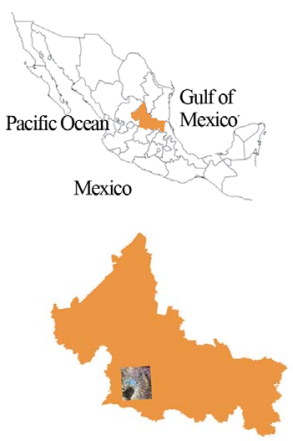

San Luis Potosi

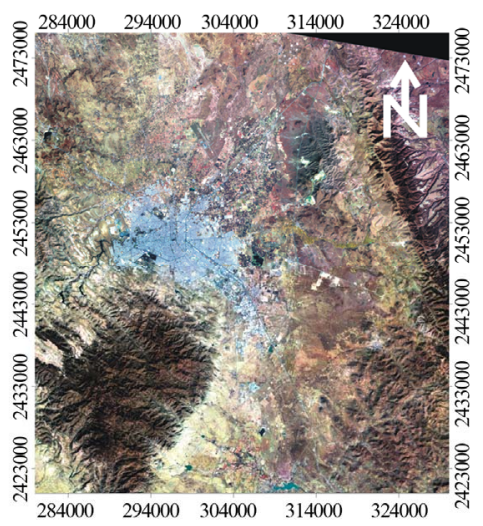

Figure 1. Location of San Luis Potosi Valley. of the aquifer $[1,11,15]$.

\section{METHODOLOGY}

The methodology used in this study is primarily based on the use of satellite imagery to assess land use changes and an analysis of the evolution of groundwater levels and subsidence problems and fractures in the VSLP urban area.

The satellite images were acquired from the United States Geological Survey (USGS). Landsat MSS (MultiSpectral Scanner) with a spatial resolution of 60 meters and 4 spectral bands from the year 1973 were used. Landsat TM (Thematic Mapper) with a 30 meter spatial resolution and 7 spectral bands were used for the years 1986, 1995 and 2000. A Digital Elevation Model (SRTM $\mathrm{DEM}$ ) with a $60 \mathrm{~m}$ resolution was also acquired from the Global Land Cover Facility (GLCF).

The evaluation of piezometric levels was performed based on piezometric maps from the years 1977, 1986, 1995, 1998 and 2007. With regard to subsidence and fractures, existing distribution maps of fracturing in the VSLP urban area from 2006 were used.

The digital image processing was performed using ENVI 4.3 software. The satellite images were subject to a process of radiometric and atmospheric correction and the DEM was corrected for missing values using an interpolation process.

The classification process used to assess land use changes was based on a supervised decision tree technique and included the four spectral bands in the MSS image and the six bands in the ETM image (the thermal band was excluded).

The Soil Adjusted Vegetation Index (SAVI) was obtained to evaluate the development of vegetation in the study area.

\section{RESULTS AND DISCUSSION}

Land use and associated changes were classified using remote sensing, as was the growth of the urban footprint, industry and agriculture in the VSLP for the years 1973, 1986, 1995 and 2000 (Figures 2 and 3).

The major changes of land use are shown in Table 1. In recent decades, there were increases in urban, crops and grassland areas, while the forest decreased considerably.

The most significant population growth occurred in the period of 1950 to 1990 , with an increase $44 \%$ between 1950 and 1970 and 55\% between 1970 and 1990. In general terms VSLP the population registered a growth rate of $4 \%$ per annum [9,16-21].

The population grew 50\% between 1970 and 1980 (INEGI, 2000). This growth is reflected in the expansion of the metropolitan area (SLP and SGS), which grew 
30\% between 1950 and 1970, 29\% between 1990 and 2000 and 32\% between 2000 and 2005 (Figure 3).

The trigger for the development of the city of SLP was the growth of industrial activity during the 1970s, which also resulted in the displacement of peri-urban crops [22].

Whereas the source of water for agricultural development in the valley has historically been surface water, the

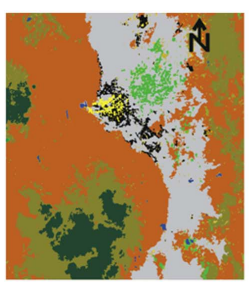

1973

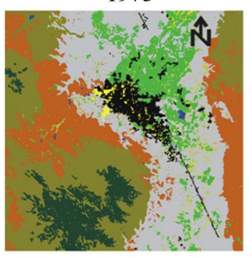

1995

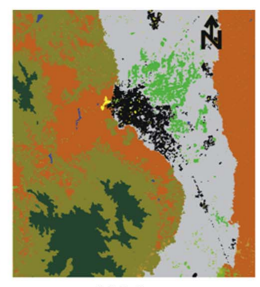
1986

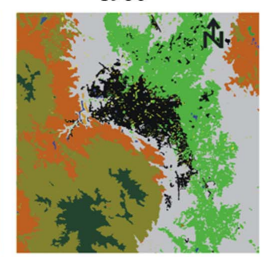

2005

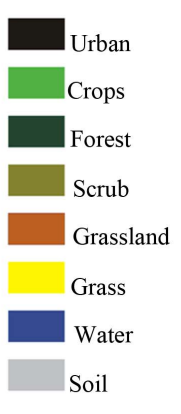

Figure 2. Classification of land use in the Valley of San Luis Potosi from satellite images for the years 1973, 1986, 1995 and 2000.

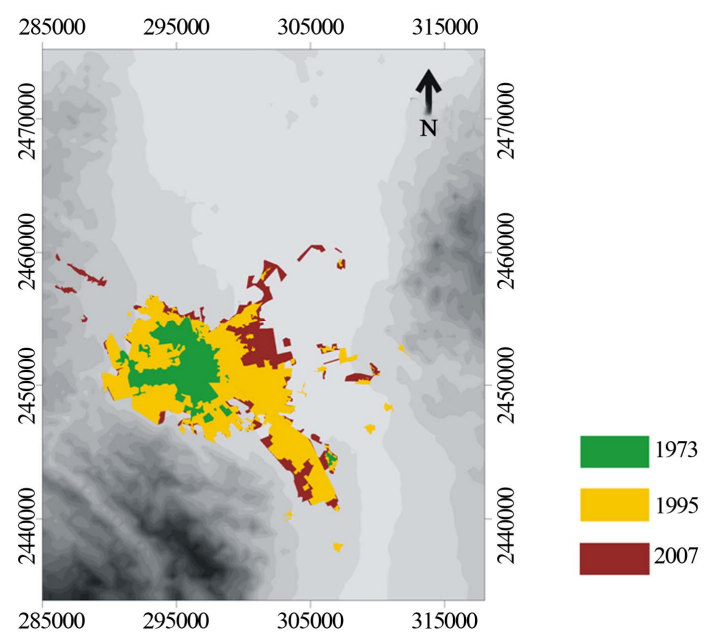

Figure 3. Growth of the urban area in the Valley of San Luis Potosi for the years 1959, 1970, 1993, 2000 and 2005 (adapted from Noyola et al., 2009).

Table 1. Changes of land use $\left(\mathrm{Km}^{2}\right)$.

\begin{tabular}{ccccc}
\hline & Urban & Crops & Grassland & Forest \\
\hline 1973 & 38 & 35 & 30 & 200 \\
1986 & 57 & 45 & 270 & 195 \\
1995 & 75 & 170 & 300 & 130 \\
2005 & 85 & 290 & 370 & 125 \\
\hline
\end{tabular}

supply in the early 1900s was provided by groundwater from the shallow aquifer and the current supply comes primarily from the shallow aquifer and wastewater [23,24].

Land use changes in the VSLP have resulted in exchanges in the use of water. While $7.7 \%$ of the volume extracted in 2006 was for industrial use and 19.8\% was for agricultural use, the volume extracted for industrial use doubled to $14 \%$ in 2008 and decreased to $4.8 \%$ for agricultural use; the demand for groundwater for human consumption is $78 \%$ [22].

Land use changes associated with human activities in the VSLP aquifer system have led to hydric stress, with the initial head loss in this analysis corresponding to 1977 (Figure 4). During this period, there were few wells in the aquifer and a drawdown had just begun. The exploitation of groundwater primarily occurred in the shallow aquifer through wells for domestic and agricultural use [1].

After a decade between 1977 and 1986, no significant changes were apparent. By 1986 (Figure 4), negative effects became evident with the deepening of a drawdown in the urban area of San Luis Potosi. During this period, the exploitation of the deep aquifer began, with drillings of wells at depths ranging between 60 and 200 meters. From 1995 to 1998, a rapid growth in the drawdown occurred (Figure 4) due to intensive exploitation of the deep aquifer, primarily for public-urban use, so that by 2007 (Figure 4), there was an overall decline in the piezometric which spread towards the southern portion of the city [1].

The depth of the cone increased $60 \mathrm{~m}$ from 1971 to 1995 [25]. The evolution of the static level for the period 1995-2001 shows that, during the 6-year period, its depth increased to $25 \mathrm{~m}$ in the center of the drawdown. That is, the level decreased $95 \mathrm{~m}$ over 30 years, with a descent rate of $3.1 \mathrm{~m} /$ year. The intense extraction and its effect on the drawdown reflects almost negligible recharge in the deep aquifer, a situation that has led to the mining of the aquifer.

One effect of the drawdown in combination with the tectonic geometry as well as differential soil compaction [26] is the appearance of fissures in the urban terrain (Figure 5).

Figure 4 shows the faults partially following the contours of piezometric levels and, in the process, streets, buildings, drainage and other infrastructure have been affected.

\section{CONCLUSIONS}

With the support of remote sensing, it was possible to analyze the dynamic changes in land use over large areas and highlight their impact on the environment. 

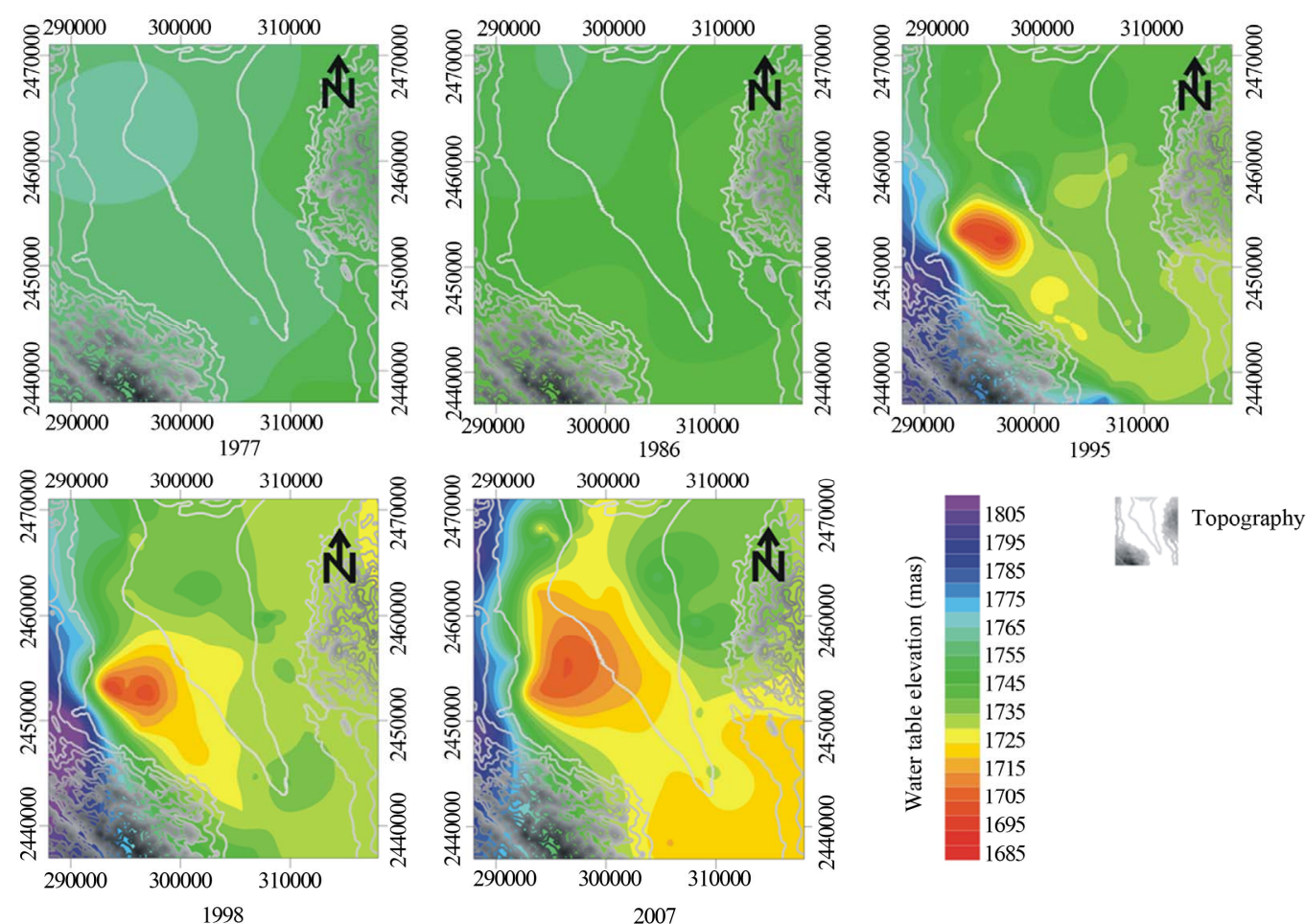

Figure 4. Evolution of groundwater levels in the Valley of San Luis Potosi for the years 1977, 1986, 1995, 1998 and 2007.

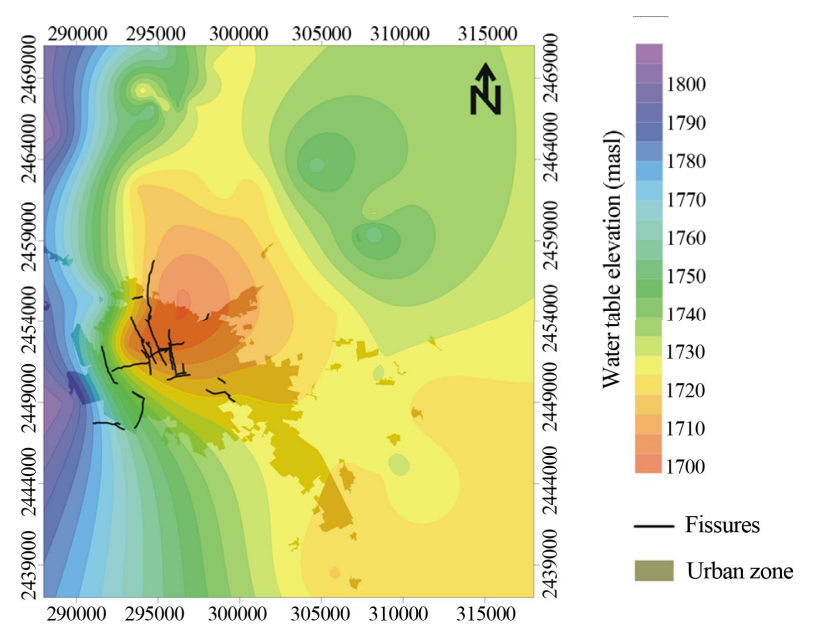

Figure 5. Combination of urban growth, the reduction in groundwater levels and fissures in the surface of the Valley of San Luis Potosi for 2007.

Rapid population growth has generated an expansion in the urban footprint which, together with a concentration of wells in the center of the valley, has created a large drawdown.

Land use changes from agricultural to industrial use brought about the demand for a constant volume and a constant supply, contributing to an overall decline in groundwater levels extending toward the industrial zone.

Subsidence is another effect of intensive groundwater extraction in the VSLP metropolitan area, which is evidenced by the appearance of fissures in the urban terrain that partially overlap with the drawdown.

The combination of different factors such as urban growth, land use changes, intensive extraction of groundwater and adverse natural conditions in the system have led to a situation of mining in the VSLP aquifer system as well as a process of subsidence in the urban terrain.

Remote sensing and geographical information systems are effective tools to evaluate environmental changes associated with anthropogenic activities.

\section{ACKNOWLEDGEMENTS}

We wish to thank the project "Social and environmental problems associated with the use and management of water in the basin of San Luis Potosi Valley” which has received funding from the Basic Science SEP-CONA-CYT-151666, in its 2010 edition. We also thank to the Water and Society Program of the College of San Luis C. A. for the support granted.

\section{REFERENCES}

[1] López-Álvarez, B. (2012) Changes in land use and its impact on the aquifer system of the Valle de San Luis Potosi, applying numerical modeling. Ph.D. Thesis, Environmental Science, Potosin Institute of Scientific and Technological Research, A.C. (IPICYT).

[2] Environment and Natural Resources (SEMARNAT) (2005) 
Report on the state of the environment in Mexico 2005. http://app1.semarnat.gob.mx/dgeia/informe 04/07 agua/r ecuadros/c_rec2_07.htm

[3] Urbina-Soria, J. and Martínez-Fernández, J. (2006) Beyond climate change. Environment and Natural Resources, National Institute of Ecology, National Autonomous University of Mexico, 287.

[4] Castillo-Escalante, I. (2007) Water quality problems in Mexico.

http://www2.ine.gob.mx/publicaciones/estudios/397/casti $\underline{\text { llo.html }}$

[5] National Water Commission (CNA) (2011) Statistics on Water in Mexico.

[6] Jiménez, B. and Marín, L. (2005) Water in Mexico, view from the academy. Mexican Academy of Sciences.

[7] Moreno, D., Campos, F. and Cisneros, F. (2004) Climatological statistics of meteorological observatory of San Luis Potosi. Institutional Commission Teaching Support.

[8] García, E. (2004) Changes to system Köppen climate classification: Mexico city, national autonomous University of Mexico, Institute of Geography.

[9] National Institute of Statistics, Geography and Informatics (INEGI) (2010) General census of population, 2010. Mexico.

[10] Groundwater Technical Committee (COTAS) and National Water Commission (CNA) (2005) Technical study regarding social conditions and aquifer hydrogeological 2411 "San Luis Potosi” in the State of San Luis Potosi. Technical Committee Aquifer Groundwater Valley San Luis Potosi.

[11] Lopez-Alvarez, B., Ramos-Leal, J.A., Santacruz-De Leon, G. and Moran-Ramirez, J. (2012) Changes in land use and its impact on the aquifer system of the Valle de San Luis Potosi, applying numerical modeling. Bulletin of the Geological Society of Mexico.

[12] Cardona, A. (1990) Origin of dissolved solids in groundwater of the valley of San Luis Potosi: Its relation to the Flow. Master's Thesis, University of Nuevo Leon.

[13] Carrillo-Rivera, J.J. (1992) Hydrogeology of the San Luis Potosí Area, Mexico. Ph.D. Thesis, University of London, London.

[14] Carrillo-Rivera, J.J., Cardona-Benavides, A. and Moss, D. (1996) Importance of the vertical component of groundwater flow: A hydrochemical approach in the valley of San Luis Potosí, México. Journal of Hydrology, 185, 23-44.

[15] Noyola-Medrano, M.C., Ramos-Leal, J.A., Domínguez-
Mariani, E., Pineda-Martínez L.F., López-Loera, H. and Carbajal, N. (2009) Factors giving rise to the mining of aquifers in arid environments: Case San Luis Potosí Valley. Mexican Journal of Geological Sciences, 24, 395410.

[16] National Institute of Statistics, Geography and Informatics (INEGI) (1950) VII general census of population, 1950. México.

[17] National Institute of Statistics, Geography and Informatics (INEGI) (1960) VIII General Census of Population, 1960. México.

[18] National Institute of Statistics, Geography and Informatics (INEGI) (1970) IX General Census of Population, 1970. México.

[19] National Institute of Statistics, Geography and Informatics (INEGI) (1980) X General Census of Population and housing, 1980. México.

[20] National Institute of Statistics, Geography and Informatics (INEGI) (1990) XI General Census of Population, 1990. México.

[21] National Institute of Statistics, Geography and Informatics (INEGI) (2000) XII General Census of Population, 2000. México.

[22] Secretary of Environment and Natural Resources (SEMARNAT) (2008) Historical archive of the water bulletin. September-December.

[23] Metropolitan Intermunicipal Agency Water Supply, Sewerage and Sanitation Related Services in the Municipalities of Cerro de San Pedro, San Luis Potosí and Soledad de Graciano Sánchez (INTERAPAS) (2010) Diagnostic study and comprehensive planning.

www.cmic.org/comisiones/sectoriales/infraestructurahidr au-

$\underline{\text { lica//varios/Taller\%20Mig/DIP\%20INTERAPAS\%20(abr }}$ il-2011)_Parte2.pdf

[24] National Water Commission (CNA) (2002) Determination of the availability of water in the aquifer San Luis Potosí, San Luis Potosí Estate.

[25] National Water Commission (CNA) (1996) Hydrogeological survey of groundwater pollution in the industrial zone of San Luis Potosi.

[26] Arzate-Flores, J., Barbosa-Gudiño, J.R., López-Doncel, R., Pacheco-Martínez, J., Mata-Segura, J.L. and Del Rosal, A. (2008) Geological-geophysical survey to evaluate subsidence and cracks in metropolitan area of San Luis Potosi-Soledad de Graciano Sánchez. Geosciences Research. Technical Bulletin of the Institute of Geology. 